\title{
Kua mi, jeg takker deg
}

I andre vers i presten Peter Andreas Jensens kjente barnesang fra 1860-årene omtales beiteforholdene: «lkke ta de visne strå, / saftig gras du ete må! / Det gjør melken din så søt. / Her er engen frisk og bløt.» Og Birger Hannisdahls unders $\varnothing$ kelser i Tidsskriftet nr. 21/1937 viser at vitamininnholdet i melken varierer med årstid, fôring og transportforhold. Hvordan transporten virker inn, er testet i et risteforsøk (Tidsskr Nor Lægeforen 1937; 57: 1111-22).

Fra Universitetets hygieniske intitutt.

Chef: Professor, dr. med. Carl Schiøtz.

\section{Kumelk som C-vitaminkilde.}

\author{
Av Birger Hannisdahl.
}

Resymé: Titreringen er foretatt fra mikrobyrette i melkeserum med 2-6 diklofenitol som indikator, efter felning med eddiksyre og centrifugering. C-vitamininnholdet i vanlig handelsmelk $i$ Oslo viste sig i undersøkelsestiden fra begynnelsen av mai måned og til midten av juli å variere ganske betydelig. Ved undersøkelse gjennem disse årstider fikk man undersøkt melk under de forskjellige foringsformer: vinter-, overgangs- (blandings-) samt sommerforing (beite). Der blev funnet variasjoner $\mathrm{i}$ den reduserende evne (C-vitamininnholdet) fra den ene dag til den annen, med nogen tendens til stigning utover den tid undersøkelsene blev foretatt fra begynnelsen av mai og til midten av juli.

Den reduserende evne - C-vitamininnholdet - var i disse melkesorter størst i helmelk, verdier fra 2,0 og op til 11,7 mgr. ascorbinsyre pr. liter melk. Gjennemsnittsverdi 6,7 mgr. pr. liter ved 20 dagers titreringer.

I de øvrige former av handelsmelk i Oslo viste undersøkelsene en lavere reduserende evne. Således blev funnet verdier fra $0,9 \mathrm{og}$ op til 3,7 mgr. pr. liter skummet flaskemelk, for kefirmelk verdier fra 1,4 op til 4,1 mgr. pr liter - i kjernemelk blev funnet reduserende evne (C-vitamininnhold) fra 1,4 op til 5 mgr. pr. liter - i lavpasterurisert, søt flaskemelk blev funnet verdier fra 1,8 op til 11,3 mgr. pr. liter melk.

Den reduserende evne (C-vitamininnholdet) i varm, nysilt, tilbragt melk fra melkeprodusenter noer Oslo viste sig i undersøkelsestiden fra 24. mai til 27. juni 1937 å ligge adskillig høiere enn de vanlige former for handelsmelk i Oslo by, med verdier fra 12,2 og op til 30,7 mgr. ascorbinsyre pr. liter melk. Gjennemsnittsverdi 18,5 mgr. pr. liter ved 22 dages titreringer.

For å undersøke transportens innvirkning på den reduserende evne (C-vitamininnholdet) blev justerte melkeprøver rystet i 1 døgn under lufttilgang, i vakuum i klar kolbe samt i vanlig transportspann. Det viste sig at rystning under tilgang på lys og luft nedsatte den reduserende evne (C-vitamininnholdet). Under klarvær synes lyspåvirkningen å være den dominerende av disse faktorer.

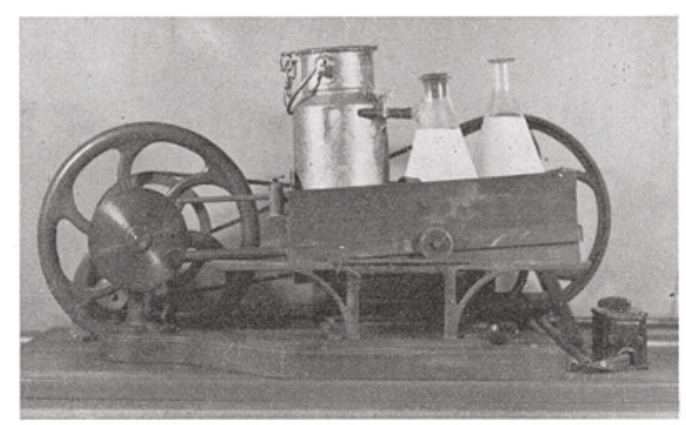

Rystemaskin med slede hvori er anbragt melkeprøvene som skal rystes. Sleden beveges frem og tilbake i en gyngende bevegelse.

Opstilles et menneskes C-vitaminbehov som svarende til 40-50 mgr. ascorbinsyre pr. dag, vil man se at den vanlige handelsmelk $i$ Oslo, efter de her foretatte undersøkelser, ikke kan ansees som tilstrekkelig C-vitaminkilde til å kunne dekke det daglige behov, selv ved et daglig konsum av 1 liter melk pr. individ. I det daglige kosthold samt scerlig ved ensidige melkedieter gjennem nogen tid bør dette forhold erindres. Helmelken og den lavpasteuriserte melk vil dog, ved et daglig konsum av 1 liter være av nogen betydning som $\mathrm{C}$-vitaminkilde - ved siden av C-vitamintilførsel gjennem andre næringsmidler.

Varm, nysilt melk fra leverandører $i$ noerheten av byen er langt mer verdifull som C-vitaminkilde - om heller ikke denne sort melk alene kan ansees som tilstrekkelig til å dekke C-vitaminbehovet. Dette er tilfellet selv om man regner med et melkekonsum av 1 liter melk pr. individ pr. dag. Der må også tilføres C-vitamin fra andre kilder for å kunne tilfredsstille det daglige behov. 